\title{
Ocular malignant melanoma in South African blacks
}

\author{
BENJAMIN MILLER, CYRIL ABRAHAMS, G. C. COLE, \\ AND NEVILLE S. F. PROCTOR \\ From the Department of Ophthalmology and School of Pathology, University of the Witwatersrand, \\ and the South African Institute for Medical Research, Johannesburg, South Africa
}

SUMMARY The incidence of primary ocular malignant melanoma in blacks during the last 25 years in a large part of the Transvaal Province of South Africa is reported. Only 8 cases were diagnosed, 1 uveal, 4 conjunctival, and 3 orbital. During this same period 153 cases of primary ocular malignant melanoma were diagnosed in whites. The rarity of these tumours among blacks is stressed and the reasons for this infrequent incidence discussed.

Most cases of ocular malignant melanomas occur in the uveal tract. It is well recognised that this tumour is rare among blacks. Paul et al. ${ }^{1}$ collected only 24 cases of malignant melanoma of the uvea in Negroes from a series of approximately 4000 cases of this tumour from the files of the Armed Forces Institute of Pathology during a 32-year period (1930-61). Shields ${ }^{2}$ in a study at the Will's Eye Hospital found only 1 black patient with a uveal malignant melanoma as against 350 whites.

Malignant melanoma of the conjunctiva is rare in all race groups. Yanoff and Fine ${ }^{3}$ noted only 6 cases in the files of the Armed Forces Institute of Pathology in a 21-year period (1952-73) and Duke-Elder ${ }^{4}$ and Kielar $^{5}$ commented that this tumour is rare in Negroes.

In this paper an attempt is made to determine the incidence of ocular malignant melanoma in South African blacks.

Table 1 Ocular malignant melanoma in blacks (1954-78)

\begin{tabular}{lllll}
\hline Case & Sex & Age & Ocular tissue & History \\
\hline 1 & F & 40 & Conjunctiva & - \\
2 & F & 54 & Conjunctiva & - \\
3 & M & 60 & Orbit* & Spindle cell B \\
4 & M & 4 & Orbit & Spindle cell B \\
5 & M & 56 & Conjunctiva & Epithelioid \\
6 & M & 59 & Orbit & Epithelioid \\
7 & F & 49 & Uvea & - \\
8 & M & 21 & Conjunctiva & \\
\hline
\end{tabular}

* Only the orbital and uveal tumours were classified according to the Callender classification.

Correspondence to Dr. B. Miller, Department of Ophthalmology, Rambam Medical Center. Technion-Faculty of Medicine, Haifa, Israel.

\section{Materials and methods}

The Department of Pathology at the South African Institute for Medical Research receives specimens from a large part of the Transvaal Province. The black population in this area is approximately 8 million and the white to black ratio is approximately $1: 4$. During the 25 year period 1954-78 the number of ocular malignant melanoma in blacks and whites diagnosed in this department was assessed.

\section{Results}

There were 153 cases of primary ocular malignant melanoma in whites and only 8 cases in blacks. In the latter group 5 were male and 3 female (Table 1). The median age was 43 years. These tumours were made up of 4 malignant melanomas of the conjunctiva and 1 of the uvea. In 3 cases (patients 3,4 , and 6 in Table 1) the site of origin of the tumour could not be determined, as the tumour had infiltrated the orbit widely. They were classified as orbital malignant melanoma.

As uveal malignant melanomas are rare in blacks, it was felt that it would be worthwhile documenting the clinical details of the one patient with this tumour.

\section{CASE REPORT}

The patient was a 49-year-old black female who was first seen at St John's Eye Hospital in December 1974 complaining of pain and loss of vision in her right eye for the last few months. On examination visual acuity was light perception in the right eye and $6 / 9$ corrected in the left. The intraocular pressure was 0 in the right eye and $15 \mathrm{mmHg}$ in the left. The left eye appeared completely normal. The right eye was injected and 


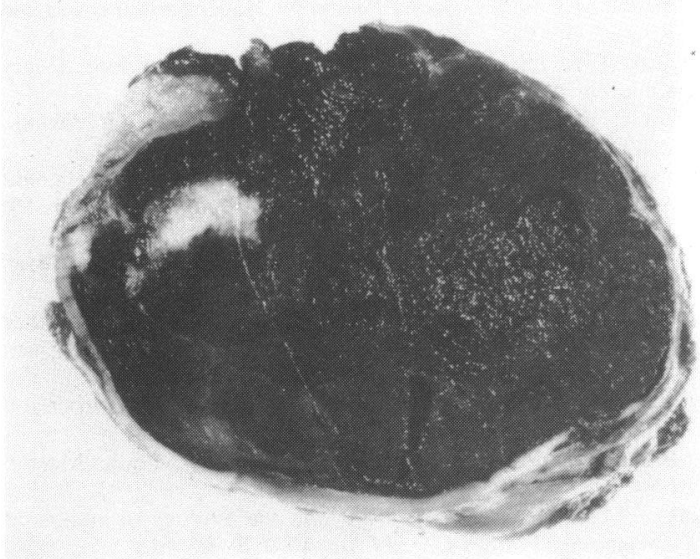

Fig. 1 Macroscopic view of a section through the globe showing diffuse infiltration by a densely pigmented tumour, with rupture of the sclera.

there were a vascularised cornea, flat anterior chamber, fixed dilated pupil, rubeosis of the iris, and cataractous lens. The diagnosis made initially was phthisis bulbi probably due to chronic uveitis. However, laboratory and radiological tests for uveitis failed to confirm this. The patient was treated symptomatically for pain and received topical steroid therapy. As the symptoms improved she did not return to follow-up. She reappeared 3 years later in December 1977 with a right eye that was blind, proptotic, and in-rotated with a perforation of the temporal sclera, through which a black mass was seen

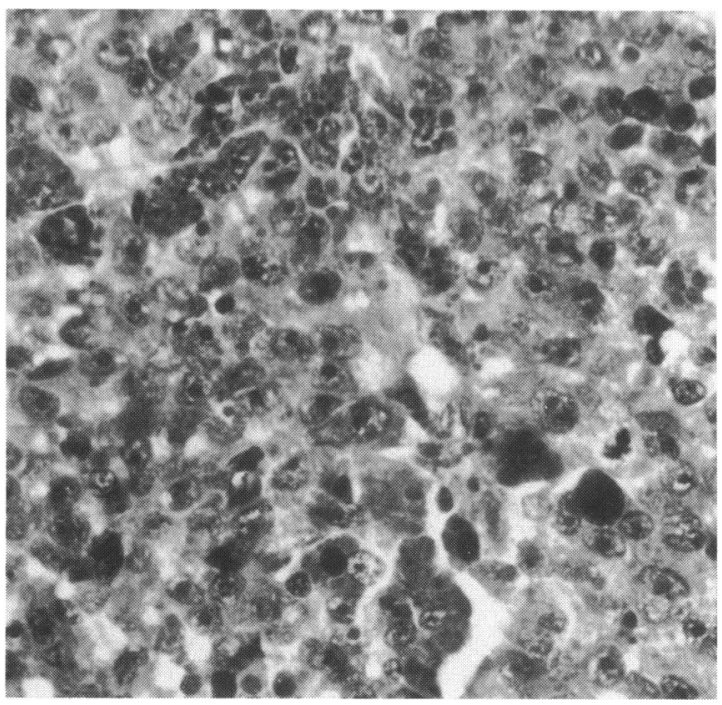

Fig. 2 Histological section of the tumour showing a predominantly epithelioid cell malignant melanoma. (Haematoxylin and eosin, $\times 540$ ). protruding. Enucleation was performed and the specimen revealed a predominantly epithelioid cell malignant melanoma of the uvea which had ruptured through the sclera (Figs. 1 and 2). Laboratory tests, liver scan, and $x$-rays failed to show any distant spread. The tumour recurred in the right orbit 6 months later. Exenteration was performed, and black tumour masses, which proved to be malignant melanoma, were found to have extended into the optic canal. Investigation failed to reveal distant spread.

\section{Discussion}

Only one case of uveal malignant melanoma was diagnosed in a black patient during a 25 -year period in the Neuropathology Department of the South African Institute for Medical Research. This observation confirms the well recognised rarity of this disease among blacks. In addition during this period 3 cases of widely infiltrating orbital malignant melanomas were diagnosed. However, the site of origin could not be identified. According to Shields and Zimmerman ${ }^{6}$ clinicians are aware that a pigmented lesion in the fundus of a Negro is unlikely to be a malignant melanoma. Melanocytoma of the disc, on the other hand, is found in the pigmented races. ${ }^{7}$ Nevertheless, the ophthalmologist should always keep in mind the possibility of a malignant melanoma when treating a blind painful eye in a black patient.

It was of interest that $50 \%$ of our cases were conjunctival malignant melanomas. This is a much higher relative incidence than in whites, where conjunctival malignant melanoma is rare compared with uveal malignant melanoma. In our series of 153 ocular malignant melanomas in whites only 5 originated in the conjunctiva (3\%), an incidence very similar to that reported by Scotto et al. $^{8}$

The white to black ratio of ocular malignant melanomas in the United States has been reported by Scotto et al. ${ }^{8}$ as 8:1, whereas Yanoff and Fine 9 estimated a ratio of $15: 1$. In our series of ocular malignant melanomas the white to black ratio was 80:1 when corrected for the different racial groups in the Transvaal Province of South Africa.

The reason for the rarity of ocular malignant melanomas in blacks is not clear. This tumour does occur in other pigmented races, and this finding stimulated Boniuk ${ }^{10}$ to suggest therefore that there is a genetically determined resistance of the Negro to ocular melanoma. Lee and Merrill " found higher rates of ocular malignant melanoma in the southern United States than in the north, probably because of a greater exposure to ultraviolet light in the south. They suggested that the skin, in response to sunlight, produces a 'solar circulating factor' which is responsible for producing intraocular malignant melanoma. 
The deeply pigmented skin of blacks may prevent the production of this factor and hence the appearance of intraocular malignant melanoma. The conjunctiva, on the other hand, is not pigmented and hence is not protected from direct exposure to ultraviolet light. This may fit with the observations in the South African blacks, among whom uveal melanomas are exceptionally rare, whereas conjunctival melanomas are relatively more common.

\section{References}

1 Paul EV, Parnell BL. Fraker M. Prognosis of malignant melanoma of the choroid and ciliary body. Int Ophthalmol Clin 1962; 2: 387.

2 Shields JA. Current approaches to the diagnosis and management of choroidal melanomas. Surv Ophthalmol 1977; 21: 443-63.
3 Yanoff M, Fine BS. Ocular Pathology. Hagerstown, Harper and Row, 1975: 635.

4 Duke-Elder S. System of Ophthalmology. London: Henry Kimpton, 1965; 8: 1219.

5 Kielar RA. Limbal melanoma in a Negro. Arch Ophthalmol 1972; 87: 392-5.

6 Shields JA, Zimmerman LE. Lesions simulating malignant melanoma of the posterior uvea. Arch Ophthalmol 1973; 89: 466-71.

7 Reese AB. Tumours of the eye. Hagerstown: Harper and Row, 1976: 174.

8 Scotto J, Fraumeni JF, Lee JAH. Melanoma of the eye and other noncutaneous sites: epidemiologic aspects. J Natl Cancer Inst 1976; 56: 489-91.

9 Yanoff M. Fine BS. Ocular Pathology. Hagerstown: Harper and Row, 1975: 657.

10 Boniuk M. Ocular and Adnexal Tumours. St. Louis: Mosby, 1964: 205.

11 Lee JAH. Merrill JM. Sunlight and the etiology of malignant melanoma: a synthesis. Med J Aust 1970; ii: 846-51. 